Lincoln, W. S., R. F. L. Thomason, 2018: A preliminary look at using rainfall average recurrence interval to characterize flash flood events for real-time warning forecasting. J. Operational Meteor., 6 (2), 13-22, doi: https://doi.org/10.15191/nwajom.2018.0602

Journal of Operational Mereorology 7 a Article

\title{
A Preliminary Look at Using Rainfall Average Recurrence Interval to Characterize Flash Flood Events for Real-time Warning Forecasting
}

\author{
W. SCOTT LINCOLN \\ NWS Lower Mississippi River Forecast Center, Slidell, Louisiana \\ RACHELLE F. L. THOMASON \\ Foundation for Louisiana, New Orleans, Louisiana
}

(Manuscript received 5 October 2017; review completed 23 March 2018)

\begin{abstract}
Characterization of flash flood severity in real-time has been highlighted by National Weather Service (NWS) service assessments for almost two decades. Current flash flood warning techniques provide limited guidance on determining potential severity of flood impacts. Recent software updates allowing for the estimation of rainfall average recurrence intervals (ARIs) in real-time help improve the nowcasting of flash flood events, but guidance is lacking on specific ARIs to use as thresholds. Researchers at the NWS Lower Mississippi River Forecast Center collected data for 24 flash flood events across the eastern United States. Reports of flash flooding were characterized based upon relative severity, and then matched to rainfall ARIs. Preliminary results from this study suggest that utilizing the 2-yr ARI contour derived from 3-h rainfall would capture approximately $\mathbf{9 0 \%}$ of flash flood reports. It also was found that more significant flash flood impacts generally became more common with an increased 3-h rainfall ARI, with major flooding of roadways or structures $(\geq 0.91 \mathrm{~m}$, or $3 \mathrm{ft}$, of inundation) becoming likely by around a 25-yr max ARI for the storm. Because of biases in the available cases used in the analysis, results are considered preliminary and subject to considerable case-by-case variability.
\end{abstract}

\section{Introduction}

The ability to recognize extreme events as they unfold and provide severity-based product wording has been highlighted by several National Weather Service (NWS) service assessments (NWS 1999, 2010, 2011). Current official NWS warning techniques provide guidance on the warn/do not warn binary decision, but only limited guidance is provided on the potential severity of the flash flood threat. However, some offices currently are evaluating experimental tools in flash flood warning decisions. One of these experimental techniques, the usage of rainfall average recurrence intervals (ARIs), may help improve flash flood nowcasting by providing an additional means of characterizing flash flood events as they unfold. Multiple studies have proposed that rainfall ARIs can be estimated in real-time to better communicate flood severity as it unfolds (Parzybok et al. 2011; Parzybok and Shaw 2012; Lincoln 2014). These efforts have led to the availability of real-time rainfall ARI estimates in NWS weather forecast office operations. Research has been limited, however, on how to best use this new information.

Another challenge to validating new flash flood nowcasting techniques is the quality of flash flood reports provided to the NWS. A low number of reports, as well as low spatial accuracy, make the data difficult to use. Reports also are subjective, potentially varying in definition across the country. The issues with NWS local storm reports (LSRs) have been widely documented and are beyond the scope of this analysis. One difficulty that must be addressed for our analysis, however, is 
the characterization of observed flash flooding. Many scales exist that attempt to categorize the magnitude of flooding, but no widely accepted, unified scale for flooding impact exists.

For any new technique to be useful in warning operations it also must be based upon information available to forecasters prior to the onset of the weather threat - otherwise no lead time would be provided. This analysis involves collection of multiple sources of rainfall data, including real-time estimates and postevent, bias-corrected estimates. Then rainfall data are compared to rainfall frequency data to estimate rainfall ARIs. Finally, rainfall ARIs are compared to flood severity to look for possible patterns that would be useful to warning forecasters.

\section{Data and methods}

\section{a. Study areas}

Data were collected for 24 flash flood events across the eastern United States that occurred from March 2012 to May 2016 (Table 1). Of these, 21 cases were in the south-central United States, and three cases were in the Midwest and northeastern United States (Fig. 1).

\section{b. Rainfall estimation}

Because the flash flood nowcasting technique being evaluated by this study is directly related to rainfall, the rainfall sources used are particularly important. Rainfall data from two sources were obtained for each event in this study. These sources differed in assumed accuracy and availability to warning forecasters.

\section{1) Multi-Radar Multi-Sensor Q3}

One radar-derived quantitative precipitation estimate (QPE) available to forecasters in near realtime is Q3, produced by the National Severe Storms Laboratory's (NSSL) Multi-Radar Multi-Sensor system (MRMS, Zhang et al. 2016). Q3 differs from single radar estimates in that it is derived from multiple radars that have been seamlessly mosaicked. Short-term model output is compared with the character of radar reflectivity to determine the best radar-rainfall relationship. Q3 rainfall estimates typically are available with a delay of $<5 \mathrm{~min}$, but no bias correction is applied to reduce radar-rainfall errors. This type of QPE source would be the most likely source for flash flood nowcasting. Q3 data in a geographic information system (GIS)-friendly format became available starting in late 2010 on the Iowa Environmental Mesonet (mesonet.agron.iastate. $\underline{\text { edu/rainfall/). }}$.

\section{2) River Forecast Center Best Estimate}

The official NWS QPE product created by the NWS River Forecast Centers (RFCs) is referred to as the multi-sensor best-estimate rainfall (also referred to as "Stage IV QPE"), and is produced using the Multisensor Precipitation Estimator software. This estimate is created by mosaicking gridded radar estimates from several individual radar sites, bias correcting the grids with automated rain gauges, then subsequently quality controlling the grids every hour. Although the bias correction reduces the uncertainty in the rainfall estimate compared to a radar-only product, estimates are only produced once per hour, and there is a 30-min delay before processing begins to allow rain gauge data to be transmitted to NWS systems. Thus, these official QPE estimates range from 0.5 to $1.5 \mathrm{~h}$ old by the time they are first available to warning forecasters for use in real-time operations, making it not particularly useful for flash flood timescales. It is included in our analysis, however, to help quantify the uncertainty directly attributable to radar-rainfall estimation techniques.

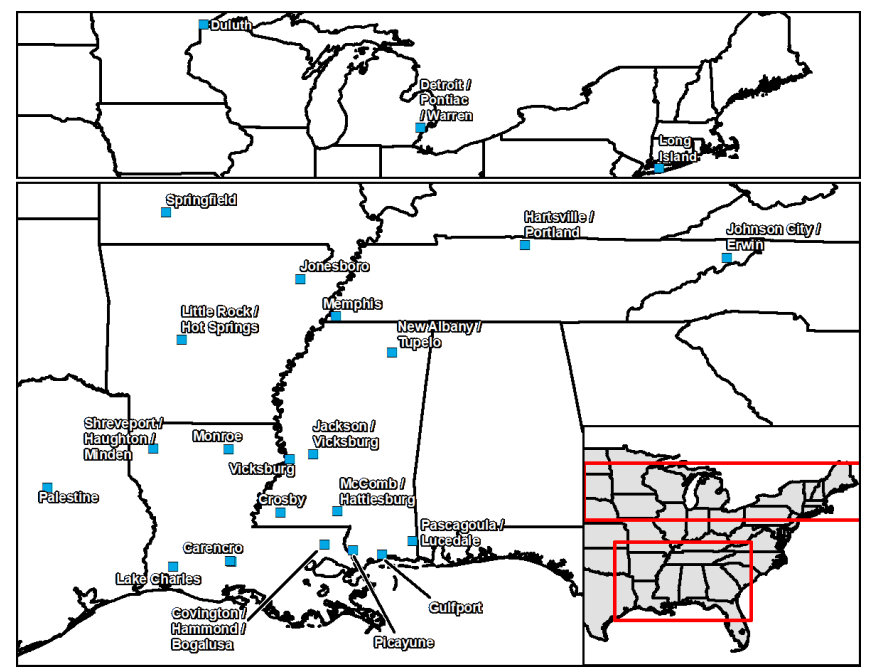

Figure 1. Map showing the approximate location of flash flood event cases used in this analysis. Click image for an external version; this applies to all tables and figures hereafter. 
Table 1. Flash flood event cases used in this analysis.

\begin{tabular}{|c|c|c|}
\hline Location(s) & State & Date \\
\hline Carencro & Louisiana & March 2012 \\
\hline Duluth & Minnesota & Jun 2012 \\
\hline Johnston City / Erwin & Tennessee & August 2012 \\
\hline Little Rock / Hot Springs & Arkansas & May 2013 \\
\hline Pascagoula / Lucedale & Mississippi & May 2013 \\
\hline Springfield & Missouri & June 2013 \\
\hline Jackson / Vicksburg & Mississippi & September 2013 \\
\hline McComb / Hattiesburg & Mississippi & February 2014 \\
\hline Crosby & Mississippi & March 2014 \\
\hline Memphis & Tennessee & June 2014 \\
\hline Islip & New York & August 2014 \\
\hline Detroit / Pontiac / Warren & Michigan & August 2014 \\
\hline Lake Charles & Louisiana & August 2014 \\
\hline Vicksburg & Mississippi & May 2015 \\
\hline Picayune & Mississippi & May 2015 \\
\hline Tupelo / New Albany & Mississippi & July 2015 \\
\hline Shreveport / Haughton / Minden & Louisiana & March 2016 \\
\hline Covington / Hammond / Bogalusa & Louisiana & March 2016 \\
\hline Monroe & Louisiana & March 2016 \\
\hline Palestine & Texas & April 2016 \\
\hline Gulfport & Mississippi & April 2016 \\
\hline Carencro & Louisiana & May 2016 \\
\hline Jonesboro & Arkansas & May 2016 \\
\hline Hartsville / Portland & Tennessee & May 2016 \\
\hline
\end{tabular}

\section{c. Rainfall frequency analysis}

Gridded rainfall estimates were compared to gridded rainfall frequency data to estimate the ARI of a particular rainfall amount occurring at a specific location. ARI rainfall estimates are available from NOAA Atlas 14 (Bonnin et al. 2006; Perica et al. 2013a, 2013b, 2015) produced by the NWS Hydrologic Design Studies Center for most areas of the United States - except for Texas ${ }^{1}$ and the Southern Regional Climate Center (SRCC) Technical Report 97-1 (Faiers et al. 1997) for Texas. Past research suggested that the highest skill in forecasting flash floods was related to the 3-h rainfall duration (Gourley et al. 2012). For the purposes of this study, the 3 -h rainfall ARI was used.

${ }^{1}$ Rainfall frequency data for Texas from NOAA Atlas 14 Volume 11 were not available during the time this study was completed and published. NOAAAtlas 14 Volume 11 is expected to be published in 2018 (www.nws.noaa.gov/oh/hdsc/current projects.html).

\section{d. Characterization of flash flood report severity}

Official reports of flash flooding (via LSRs) were collected in a GIS-friendly format from the Iowa Environmental Mesonet (mesonet.agron.iastate.edu/ request/gis/lsrs.phtml). These official reports were supplemented by reports of flooding obtained through searches of news media and social media that increased the density of reports, similar to the methods of Lincoln et al. (2017). Because of limitations in various social media platforms, retrieving crowdsourced data more than a few weeks after the event becomes increasingly difficult. Recognizing this, the Lower Mississippi RFC (LMRFC) began collecting additional crowdsourced reports for noteworthy flash floods beginning in 2012, with the original intent of capturing flood impacts from social media before the data were no longer retrievable. Events in this database were deemed "noteworthy" if (i) an NWS flash flood warning was issued, (ii) the maximum 3-h rainfall ARI was $>5 \mathrm{yr}$, (iii) at least one 
LSR was received by the NWS, and (iv) additional flood impact reports were available from crowdsourcing. A potential connection between flood events and rainfall ARIs was later recognized that led to the usage of rainfall ARI information in real-time NWS operations. To investigate ARI thresholds for warnings, it was decided to connect these social media reports, official flood reports, and ARI data.

Based upon descriptions of the impacts, flood reports were categorized based upon relative severity. Contrary to other severe weather phenomena like tornadoes, no widely accepted, unified scale exists for the characterization of flash flood impacts. Flash flood warnings issued by the NWS typically are binary (flash flooding is either expected or it is not expected), and often provide less severity information when compared to other short-fuse weather warnings. The creation of a flash flood impact scale is thus needed to evaluate flash flood nowcasting techniques against the actual impacts that flash flooding produces.

Several different scales are currently being utilized by multiple agencies and groups to attempt to differentiate among levels of flood impact. We reviewed scales provided by (i) the NWS in Manual 10-950 (www. nws.noaa.gov/directives/sym/pd01009050curr.pdf), (ii) the Federal Emergency Management Agency (FEMA) in the Damage Assessment Operations Manual (www. fema.gov/media-library/assets/documents/109040), (iii) Calianno et al. (2013) for the Severe Hazards Analysis and Verification Experiment (SHAVE), (iv) Cosgrove et al. (2015) for the NSSL mPING project (mping.nssl.noaa.gov/types.php), (v) Kreibich et al. (2009), (vi) Lincoln (2014) and Lincoln et al. (2017), and (vii) Schroeder et al. (2016). Scales reviewed for this study are summarized by Table 2 .

There remain strengths and weaknesses with each of the mentioned flooding severity scales. Some scales, such as SHAVE, have categories with a large human impact component (water rescues, injuries). The same severity of natural hazard (flood severity) may cause varying levels of human impact based upon complicated and difficult-to-predict human behavior. Other scales focus on quantity, rather than severity, of flood impacts ("extensive inundation of structures" in the NWS scale). Although not perfect, the most appropriate flash flood impact scale to compare to rainfall ARI would be one that focuses on permanent infrastructure and structures that remove the potential ambiguity associated with the movement of people and vehicles. As such, we only compared rainfall ARIs to the flooding of roadways and structures. Roadway and structure flooding was further broken down into two categories - minor and major. The differentiation between "minor" and "major" was a manual process based upon pictures of flooding or text in an LSR. Flooding was assumed to be minor unless an inundation depth approximately $\geq 0.91 \mathrm{~m}$ (3 ft) was estimated. Water of any depth inundating a major highway (interstate or expressway) also yielded a "major" classification.

\section{e. Tying flash flood reports to rainfall ARI}

Reports of flash flooding were tied to the causative rainfall ARI in two ways - first by looking at the rainfall ARI for the immediate area near the report of flooding and second by looking at the event as a whole (Fig. 2). The data collected from each approach will potentially help answer two different, but related questions:

1) If $n$-yr ARI contour is used as the warning box shape, what percent of flash flood reports would be expected to fall inside or outside of the polygon?

2) If a storm produces rainfall of $n$-yr ARI, what is the chance of any flash flood report in the vicinity? What is the chance of $\geq 1$ report of major flash flooding?

For evaluating which ARI to use as guideline for warning extent, reports of flash flooding are tied to highest ARI within $0.1 \mathrm{deg}$ (approximately $4 \mathrm{~km}$ ). For evaluating which ARI to use as a guideline for determining maximum event flash flood severity, reports of flash flooding are tied to the highest ARI for the

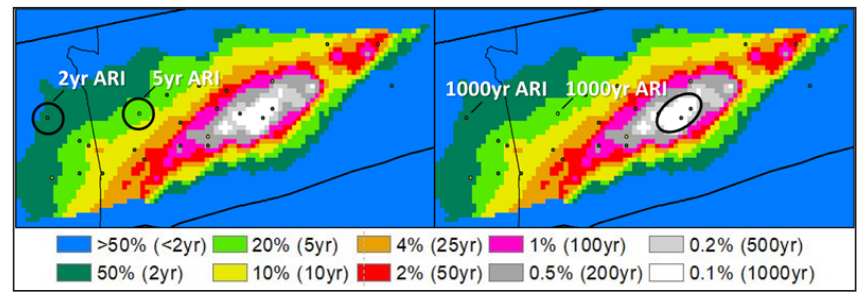

Figure 2. Illustration of how reports of flash flooding were tied to rainfall ARI values. For evaluating which ARI to use as guideline for warning extent, reports of flash flooding are tied to highest ARI within $0.1 \mathrm{deg}$ (approximately 4-km; left). For evaluating which ARI to use as a guideline for determining maximum event flash flood severity, reports of flash flooding are tied to the highest ARI for the event as a whole (right). 
Table 2. Comparison of various scales of flood impact (see discussion in section $2 b$ ) ranked relatively from least severe (top) to most severe (bottom). Indistinct classifications are indicated with an asterisk.

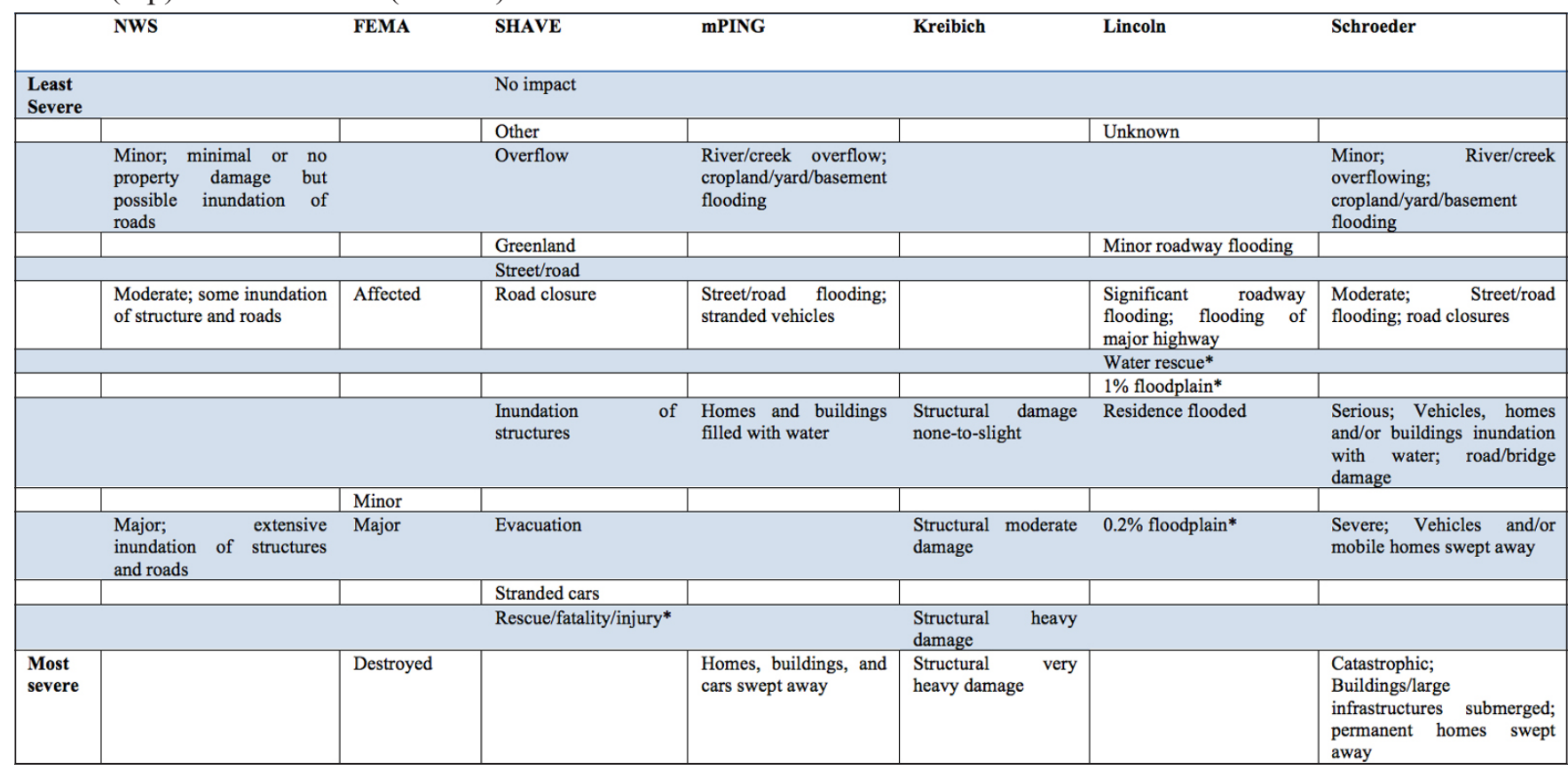

event as a whole. Determining each event's extent was a somewhat subjective process, but was approximately conterminous with the extent of the 2-yr or greater 3-h rainfall ARI, plus additional 2-yr or greater ARI areas connected by at least $1.25 \mathrm{~cm}(0.5 \mathrm{in})$ of rainfall. Using this procedure generally resulted in flood reports being displaced $<16 \mathrm{~km}(10 \mathrm{mi})$ from the event maximum ARI, though one very expansive event included an LSR that was approximately $209 \mathrm{~km}(130 \mathrm{mi})$ away.

\section{Results}

\section{a. Rainfall ARI in the vicinity of flash flood reports}

For all reports of flash flooding combined, approximately $50 \%$ and $90 \%$ of all reports would be captured using the 25-yr, 3-h rainfall ARI contour and the 2-yr, 3-h rainfall ARI contour, respectively (Fig. 3), when using RFC best-estimate rainfall as the source. Little difference was noted when subdividing by specific flood impact with approximately $50 \%$ and $90 \%$ of roadway flooding captured using the 25-yr and 2-yr ARI contours, respectively (Fig. 4a), and approximately $50 \%$ and $90 \%$ of structure flooding captured using the 50-yr and 5-yr ARI contours, respectively (Fig. 4b). The exact percentage differed slightly depending on rainfall source (RFC best estimate or Q3 radar only). It also was noted that these values varied widely among individual

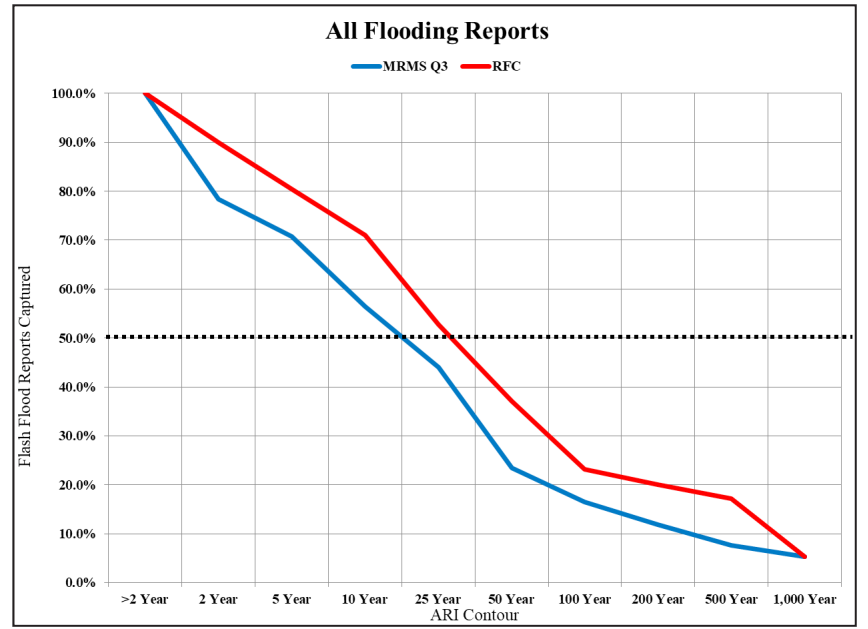

Figure 3. Cumulative probability of flash flood reports being captured by contours of 3-h rainfall ARIs for all reports of flash flooding. Both rainfall sources, MRMS Q3 available in near real time and RFC best-estimate available at least 30-min after the event, are displayed.

flash flood events (Fig. 5). No obvious grouping of events by region was observed. Next, the events were broken up by pre-event soil moisture condition (Fig. 6), as determined by the United States Geological Survey (USGS) streamflow percentile (waterwatch.usgs. gov/). The USGS streamflow percentile was chosen as a proxy for soil moisture because of the very limited availability of observed and modeled soil moisture data 


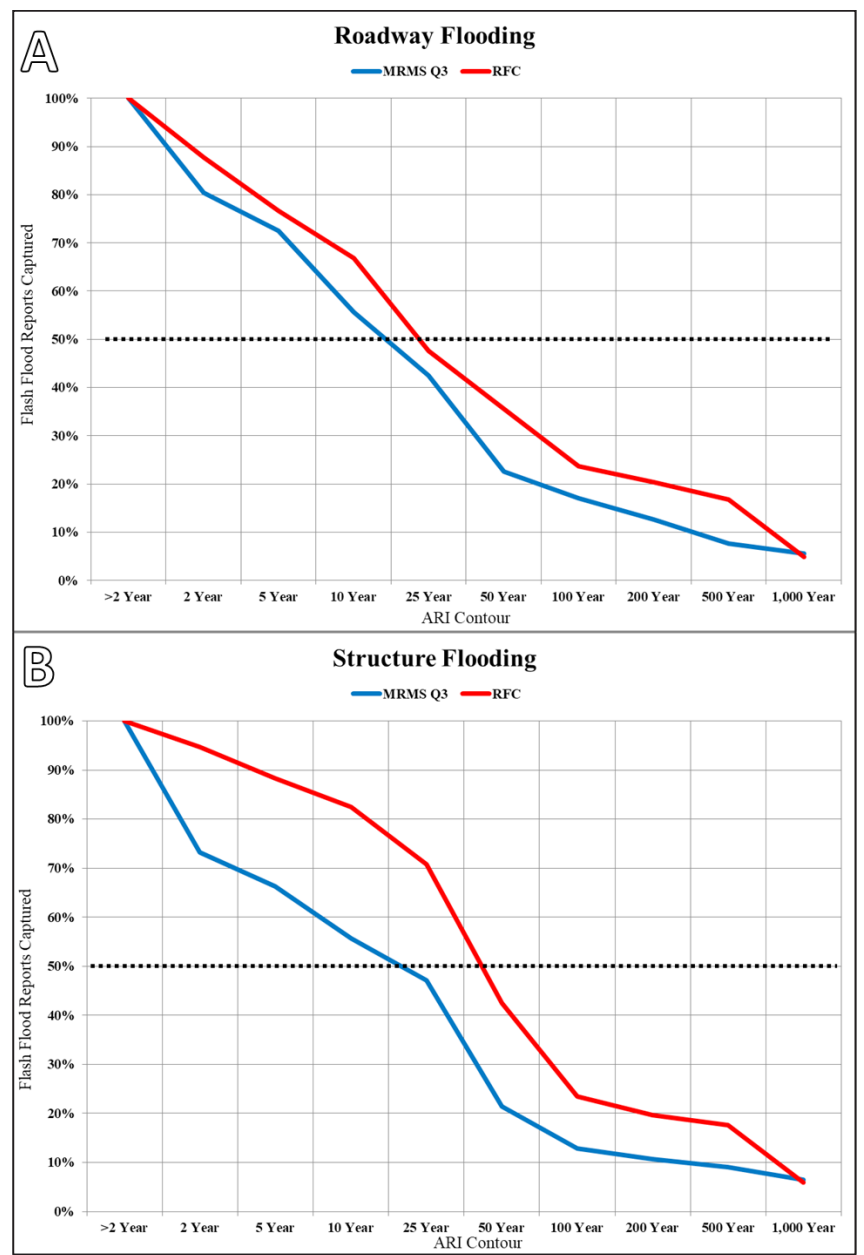

Figure 4. Cumulative probability of flash flood reports being captured by contours of 3-h rainfall ARIs for only reports of flash flooding impacting roadways (top) and only reports impacting structures (bottom). Both rainfall sources, MRMS Q3 available in near real time and RFC best-estimate available at least 30-min after the event, are displayed.

and experience at the LMRFC using streamflow data as a reasonable alternative. In cases with above normal soil moisture prior to the rainfall event, much lower intensity rainfall (determined by 3 -h rainfall ARIs) was required to produce the same flood impact; the 3-h rainfall ARI contour that would capture approximately $50 \%$ of the flash flood reports was reduced from $25 \mathrm{yr}$ to $5 \mathrm{yr}$.

\section{b. Maximum ARI for the entire flash flood event}

For each case, the maximum 3-h rainfall ARI was tied to every flash flood report. The number of flash flood reports tied to a specific rainfall ARI was calculated and

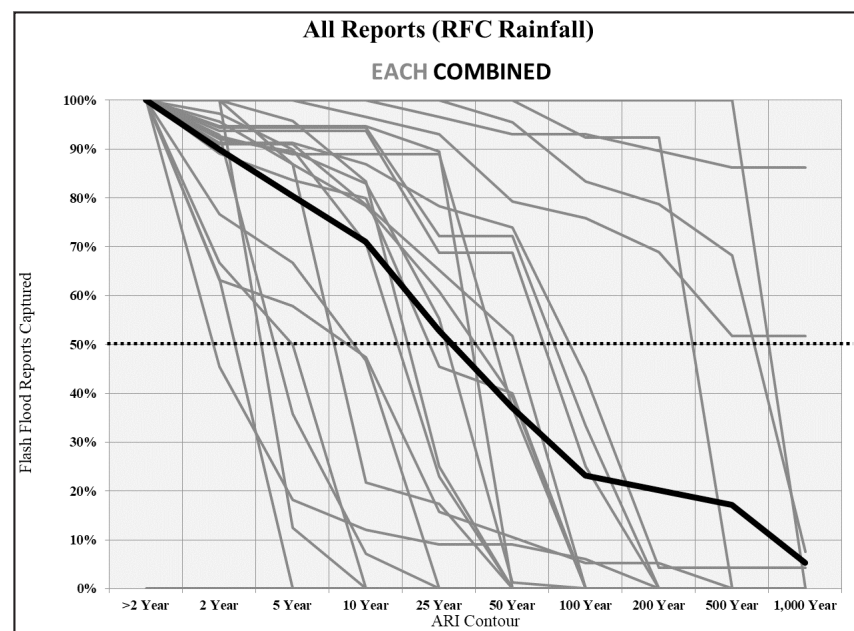

Figure 5. Cumulative probability of flash flood reports being captured by contours of 3-h rainfall ARIs for all reports of flash flooding, separated out into individual events. Rainfall source is RFC best-estimate only.

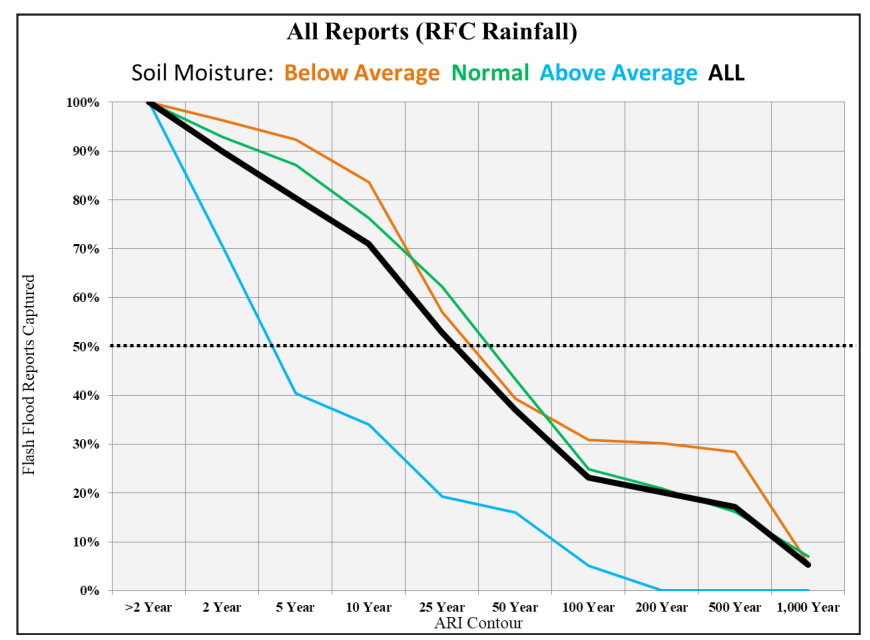

Figure 6. Cumulative probability of flash flood reports being captured by contours of 3-h rainfall ARIs for all reports of flash flooding, separated out into categories for soil moisture. Soil moisture is estimated by the USGS streamflow percentile for the basin encompassing the flash flood event. Rainfall source is RFC best-estimate only.

the reports were again subdivided by impact. Each flash flooding case studied in this analysis had at $\geq 1$ report of minor roadway flooding, meaning that no null cases were evaluated. For major flooding of roadways, there was a trend toward a higher probability of a report with higher event maximum 3-h rainfall ARIs; the chance of major roadway flooding increased from $<50 \%$ at ARIs of $10 \mathrm{yr}$ and lower, to near $75 \%$ at a 50 -yr ARI and above (Fig. 7a). For the flooding of structures, little trend 
was noted between probability of occurrence and 3-h rainfall ARI; the probability of structure flooding was near $90 \%$ across all event ARIs. When looking at major flooding of structures only, there was a possible slight trend toward a higher probability of occurrence with increasing ARIs, but the probability generally flattened around $30 \%$ for most ARIs (Fig. 7b). Unfortunately, the low number of flash flood cases with event maximum ARIs of $\leq 25$ yr (lower rainfall severity) reduced the confidence in each of these trends. Removal of ARIs with $<5$ cases eliminated most evidence of the noted trends.

\section{Discussion}

It was found that $3-\mathrm{h}$ rainfall ARI has some association to flash flood impact, but this association was limited. When looking at ARIs as a potential guide for spatial extent of warnings, wide differences were noted between individual events, with only pre-event soil moisture being a potential way of narrowing down this uncertainty. Based upon our analysis, a warning forecaster would expect to capture approximately $50 \%$ of flash flood reports when using the 25-yr ARI and 90\% of flash flood reports when using the 2-yr ARI. Although event-by-event spread remained at this capture rate, most events are clustered near this value and it leans on the side of a false alarm instead of a missed event. Note that, on average, Q3 rainfall from MRMS was biased slightly low compared to RFC rainfall, meaning that a slightly lower Q3 rainfall ARI produced the same flash flood report capture rate as the RFC rainfall. This difference may suggest an ARI reduction of up to one full category (e.g., $100 \mathrm{yr}$ to $50 \mathrm{yr}, 10 \mathrm{yr}$ to $5 \mathrm{yr}$, etc.) when applying these results in warning operations that utilize Q3 rainfall.

Using contours from 3-h rainfall ARIs also has implications for the size of flash flood warnings. For the cases analyzed by this study, the mean warning area was $18335 \mathrm{~km} 2$ (7079 mi2), while the mean area enclosed by the 2-yr ARI contour was $9987 \mathrm{~km} 2$ (3856 mi2) (Table 3). Averaging the differences in size between official warnings and the 2-yr ARI contour for each event yielded a mean reduction of $27.4 \%$; this potential reduction in warned area yielded only a small change in the flash flood report capture rate average across events, from $95.9 \%$ (official flash flood warnings) to $88.7 \%$ (2yr ARI contour, Table 4). Increasing the ARI used as a contour for warning extent decreased the warned area but also reduced the capture rate for flash flood reports.

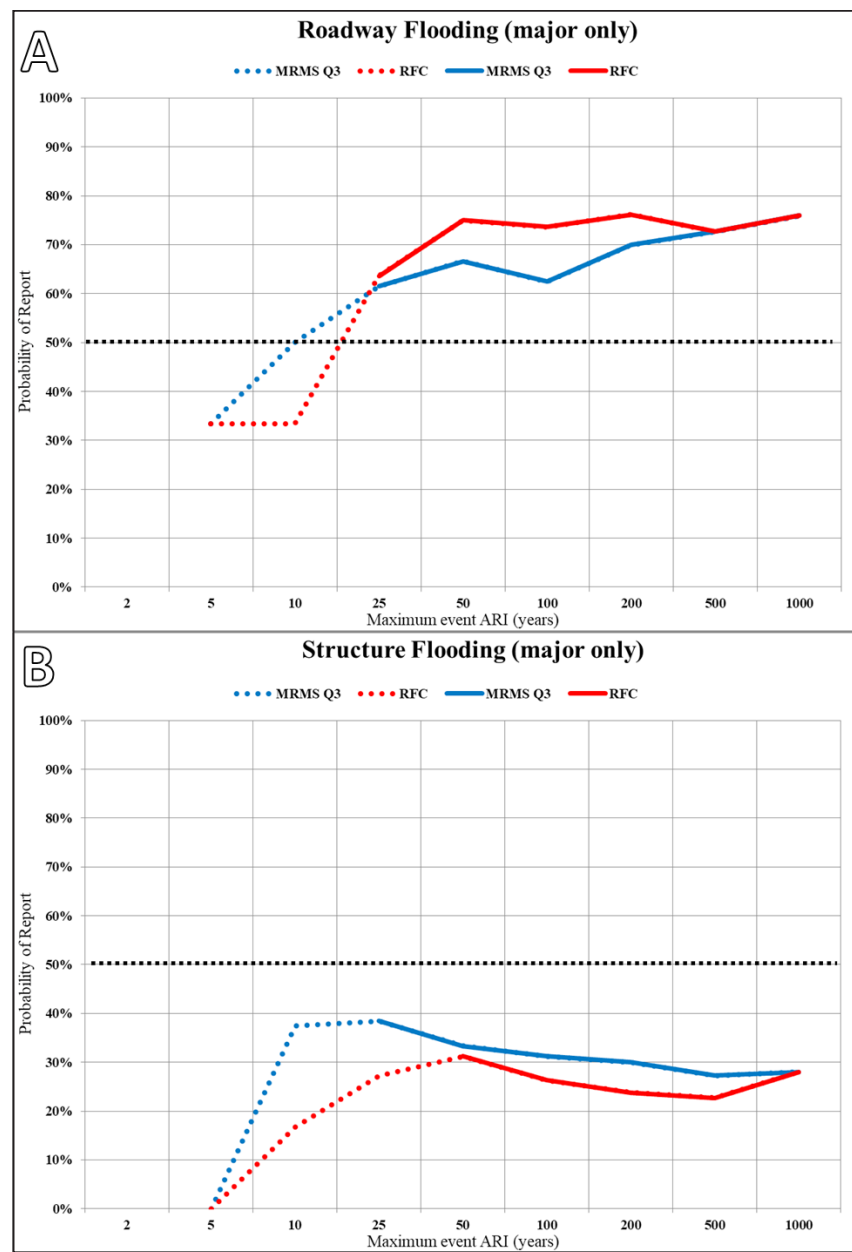

Figure 7. Cumulative probability of flash flood reports based upon the event maximum 3-h rainfall ARI for only reports of major flash flooding $[>=0.91-\mathrm{m}(3-\mathrm{ft})$ inundation] impacting roadways (top) and only reports of major flash flooding $[>=0.91-\mathrm{m}(3-\mathrm{ft})$ inundation] impacting structures (bottom). Both rainfall sources, MRMS Q3 available in near real time and RFC bestestimate available at least 30-min after the event, are displayed. Dashed lines correspond to areas with a sample size of five (5) events or fewer.

An illustration of official warning extents compared to 2-yr, 3-h rainfall ARI is shown by Fig. 8.

When looking at ARIs as a guide for categorizing the potential severity of a flash flood event, the association between 3-h rainfall ARI and the chance of a given flood impact also was limited. Because of the bias of our sample, only cases that had reports of flooding were analyzed (i.e., no null events); our study would suggest a $100 \%$ chance of $\geq 1$ flash flood impact at all ARIs $>2$ yr. The association between major roadway flooding and rainfall ARI was the strongest found in 
Table 3. Average area of official NWS flash flood warnings compared to area enclosed by 2-, 5-, 10-, and 25-yr rainfall ARIs (using RFC best-estimate rainfall). Note that the percent change in area from NWS warning to ARI contour is an average of the percent change for each event, and thus will not necessarily match the difference between ARI contour area average and NWS warning area average.

\begin{tabular}{|c|c|c|c|c|c|}
\hline & $\begin{array}{l}\text { NWS Warning } \\
\text { Area }\left(\mathbf{k m}^{2} ; \mathbf{m i}^{2}\right)\end{array}$ & $\begin{array}{l}\text { 2-yr ARI Contour } \\
\text { Area }\left(\mathbf{k m}^{2} ; \mathbf{m i}^{2}\right) / \\
\text { Change }(\%)\end{array}$ & $\begin{array}{l}\text { 5-yr ARI Contour } \\
\text { Area }\left(\mathbf{k m}^{2} ; \text { mi }^{2}\right) / \\
\text { Change }(\%)\end{array}$ & $\begin{array}{l}\text { 10-yr ARI Contour } \\
\text { Area }\left(\mathrm{km}^{2} ; \mathrm{mi}^{2}\right) / \\
\text { Change }(\%)\end{array}$ & $\begin{array}{l}\text { 25-yr ARI Contour } \\
\text { Area }\left(\mathbf{k m}^{2} ; \mathbf{m i}^{2}\right) / \\
\text { Change }(\%)\end{array}$ \\
\hline $\mathrm{Me}$ & & $10306 ; 3979 /-27.4 \%$ & $6426 ; 2481 /-53.1 \%$ & $469 ; 181 /-67.3 \%$ & $2129 ; 822 /-79.5 \%$ \\
\hline Median & $10482 ; 4047$ & $6680 ; 2579 /-32.6 \%$ & $3590 ; 1386 /-54.1 \%$ & $2893 ; 1117 /-70.1 \%$ & $1795 ; 693 /-86.8 \%$ \\
\hline
\end{tabular}

Table 4. Average capture rate for flash flood reports using official NWS flash flood warnings and the area enclosed by 2-yr, 5-yr, 10-yr, and 25-yr rainfall ARIs (using RFC best-estimate rainfall).

\begin{tabular}{|l|lllll|l|l|}
\hline & Total Reports & $\begin{array}{l}\text { Official NWS flash } \\
\text { flood warnings }\end{array}$ & $\begin{array}{l}\text { 2-yr ARI } \\
\text { Contour }\end{array}$ & $\begin{array}{l}\text { 5-yr ARI } \\
\text { Contour }\end{array}$ & $\begin{array}{l}\text { 10-yr ARI } \\
\text { Contour }\end{array}$ & $\begin{array}{l}\text { 25-yr ARI } \\
\text { Contour }\end{array}$ \\
\hline Mean & 36 & $95.9 \%$ & $88.7 \%$ & $79.0 \%$ & $73.9 \%$ & $59.7 \%$ \\
\hline Median & 27 & $100.0 \%$ & $93.3 \%$ & $89.9 \%$ & $83.3 \%$ & $67.0 \%$ \\
\hline
\end{tabular}

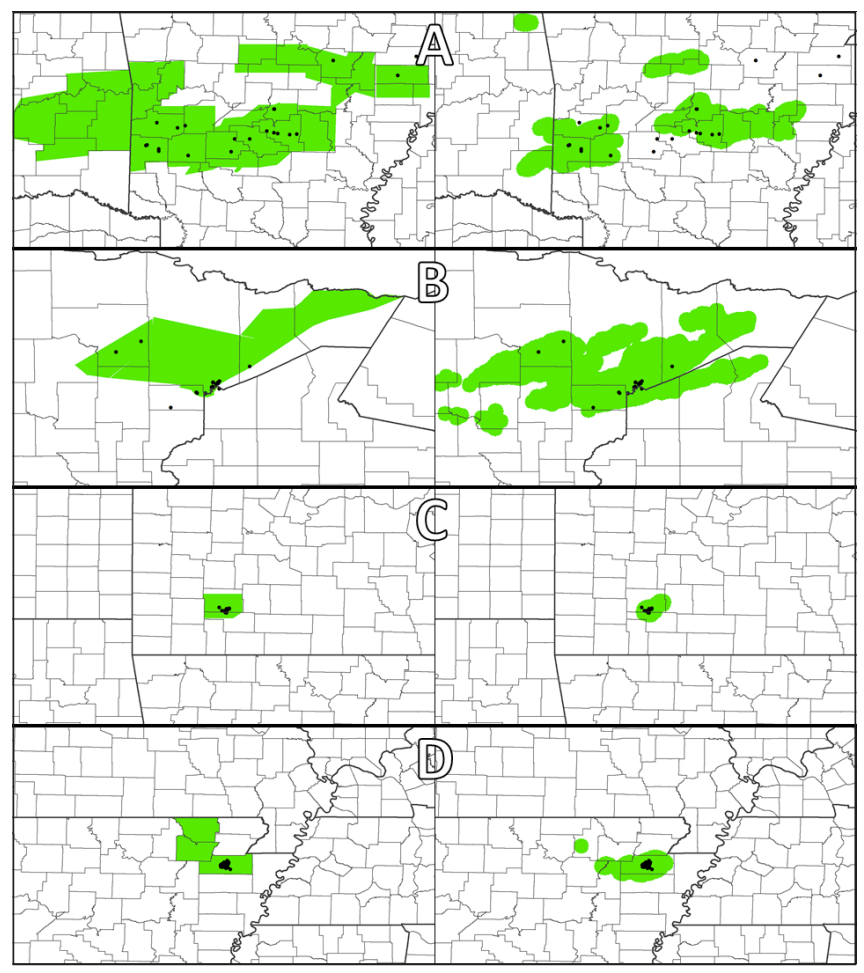

Figure 8. Illustration of several differences in shape and size between extent of operational NWS flash flood warnings (left) and extent of 3-h rainfall reaching $\geq 2$-yr ARI buffered by $4 \mathrm{~km}$ (right). Flash flood reports (block dots) were added for reference. Events shown are (a) Little Rock/Hot Springs, AR, from 2013, (b) Duluth, MN, from 2012, (c) Springfield, MO, from 2013, and (d) Jonesboro, AR, from 2016. Width of each plot is approximately $482.8 \mathrm{~km}$ (300 $\mathrm{mi})$, but this varies by up to $10 \%$ owing to the map projection. our analysis. The chance of structure flooding showed virtually no association to rainfall severity, and major flooding of structures also showed a similar trend. The limited number of cases with an event ARI maximum of $\leq 25 \mathrm{yr}$ greatly decreased confidence in any potential trends.

Attempts to break down events by region of the country and pre-event soil moisture were met with mixed results. No useful trends were noted when flash flood events were grouped by state. A possible trend was noted, however, with pre-event soil moisture, where higher soil moisture values led to lower rainfall ARIs being required for the same impacts. These results seem to suggest that warning forecasters should consider using a lower ARI during periods of wet antecedent conditions. We acknowledge, however, that using a proxy for soil moisture data instead of direct observations yields a hard-to-quantify amount of uncertainty.

There are few similar studies with which to compare our results. A study focusing on the northcentral United States conducted by the NWS Weather Prediction Center in 2017 utilized 20 flash flood cases that occurred during summer 2016 (Hammond 2018). Hammond found generally similar trends; the lower the ARI contour used, the more flash flood reports would be captured, and events with a higher rainfall ARI roughly associated with more severe flooding impacts. Their results differed, however, in the number of reports captured by each rainfall ARI contour. The 2-yr ARI contour captured only $35 \%$ of the reports compared to $90 \%$ in our study. A big difference between studies lies in the rainfall data used to calculate ARIs (N. Hammond 
2017, personal communication); Hammond (2018) utilized rainfall totals over 6-h synoptic observational periods (0000-0600 UTC, 0600-1200 UTC, etc), whereas this study utilized running 3-h accumulations of rainfall starting at the top of each hour. Using rainfall accumulations over fixed periods of time instead of running accumulations may lead to what is referred to as a "fixed-interval bias"; in the case of Hammond (2018), this would reduce 6-h rainfall totals that did not start and end exactly at synoptic hours owing to rainfall spanning multiple observational periods. Reduced 6-h rainfall accumulations due to the fixed-interval bias also would lead to reduced ARIs, and thus, an apparent reduction in the ARI necessary to capture a particular percentage of flash flood reports. Other differences between studies include the location of flash flood cases (north-central United States instead of predominantly the south-central United States) and the rainfall duration (6 $\mathrm{h}$ instead of $3 \mathrm{~h}$ ).

Verification of any flash flood nowcasting technique remains difficult owing to limitations in the flash flood report database of the NWS. Cosgrove et al. (2015) attempted to create a unified database of flash flood reports that also included more objective reports of flash flooding based upon USGS stream gauges. Most flash flood events do not coincide with a USGS stream gauge located on a small, fast-responding river basin, however, which greatly limits the usage of these reports. Differences in natural flood tendency, social vulnerability to hazards, and building codes are some of the other potential factors behind issues with flash flood reports, but they are beyond the scope of this analysis to address.

\section{Conclusions}

Twenty-four flash flood events were analyzed to compare rainfall ARIs to the severity of the resulting flash flood impact. Based upon our analysis, a potential guideline for flash flood warning polygons could be the 2-yr ARI contour of 3-h rainfall. Our analysis suggests that approximately $90 \%$ of flash flood reports would be captured (with a roughly 4-km margin), similar to the performance of official NWS flash flood warnings, and flash flood warning sizes could potentially be reduced by $>25 \%$. A potential guideline for the onset of major flooding [roadway inundation of $\geq 0.91 \mathrm{~m}$ (3 ft), flooding of major highways, and inundation of structures $\geq 0.91 \mathrm{~m} \mathrm{(3 \textrm {ft } )}$ ] would be when a 3-h rainfall event reaches the 25-yr ARI. Our analysis suggests that at this rainfall ARI, there is a $60-70 \%$ chance of major roadway flooding and a 30-40\% chance of major structure flooding.

Results from this preliminary study should be used with caution, however, because of significant biases in the sample of cases analyzed and noted differences between studies. Sample cases were selected because rainfall and flash flood report data were already available; in other words, events were selected specifically because they experienced flooding, and no null events were included. Only a few events did not exceed the 5-yr ARI in our study, making estimates of flash flood severity based upon maximum 3-h ARI very uncertain. Future work should specifically include null events in the sample to improve the analysis. Instead of selecting events because flooding occurred, events should be selected based upon a threshold of 3-h rainfall ARI being exceeded. An increased number of cases at all ARIs would further increase confidence in the usage of rainfall ARI as a method of characterizing flash flood severity.

Acknowledgments. This study was partially funded by the North Gulf Institute Diversity Internship Program. The authors acknowledge Weather Underground for private weather station data. Daryl Herzmann and the Iowa Environmental Mesonet from Iowa State University are acknowledged as the source for processed NSSL Q3 radar precipitation data. The authors also thank David Welch and J. J. Brost for their helpful comments, as well as the peer reviewers who provided valuable feedback.

\section{REFERENCES}

Bonnin, G. M., D. Martin, B. Lin, T. Parzybok, M. Yekta, and D. Riley, 2006: NOAA Atlas 14: Precipitationfrequency atlas of the United States. United States DOC/NOAA/NWS, Vol. 2, Ver. 3, 295 pp. [Available online at www.nws.noaa.gov/oh/hdsc/PF documents/ Atlas14_Volume2.pdf.]

Calianno, M., I. Ruin., and J. J. Gourley, 2013: Supplementing flash flood reports with impact classifications. J. Hydrol., 477, 1-16, Crossref. 
Cosgrove, B., W. Hogsett, F. Barthold, T. Workoff, D. R. Novak, J. J. Gourley, and M. Klein, 2015: A real-time multi-source flash flood verification database in support of NOAA/NWS Weather Prediction Center research and operations. Preprints, 29th Conf. on Hydrology, Phoenix, AZ, Amer. Meteor. Soc., 5.2. [Available online at ams. confex.com/ams/95Annual/webprogram/Paper259796. html.]

Faiers, G. E., B. D. Keim, and R. A. Muller, 1997: Rainfall frequency/magnitude atlas for the south-central United States. SRCC Tech. Rep. 971, 41 pp. [Available online at www.losc.1su.edu/tech97 2.pdf.]

Gourley, J. J., J. M. Erlingis, Y. Hong, and E. B. Wells, 2012: Evaluation of tools used for monitoring and forecasting flash floods in the United States. Wea. Forecasting., 27, 158-173, Crossref.

Hammond, N., 2018: A comparison between summer 2016 flash flood observations and rainfall ARIs across the north-central United States. Preprints, 32nd Conf. on Hydrology, Austin, TX, Amer. Meteor. Soc., 42. [Available online at ams.confex.com/ams/98Annual/ webprogram/Paper326494.html.]

Kreibich, H., K. Piroth, I. Seifert, H. Maiwald, U. Kunert, J. Schwarz, B. Merz, and A. H. Thieken, 2009: Is flow velocity a significant parameter in flood damage modelling? Nat. Hazards Earth Syst. Sci., 9, 1679-1692, Crossref.

Lincoln, W., 2014: Analysis of the 15 June 2013 isolated extreme rainfall event in Springfield, Missouri. $J$. Operational Meteor., 2 (19), 233-245, Crossref.

, R. F. L. Thomason, M. Stackhouse, and D. S. Schlotzhauer, 2017: Utilizing crowd-sourced rainfall and flood impact information to improve the analysis of the north-central Gulf Coast flood event of April 2014. J. Operational Meteor., 5 (3), 26-41, Crossref.

NWS, 1999: South Texas Floods, October 17-22, 1998. NWS Service Assessment, 24 pp. [Available online at www.weather.gov/media/publications/assessments/ texasflood98.pdf.]

, 2010: Southeast United States Floods, September 18-23, 2009. NWS Service Assessment, 71 pp. [Available online at www.weather.gov/media/ publications/assessments/se floods10.pdf.]

, 2011: Record Floods of Greater Nashville: Including Flooding in Middle Tennessee and Western Kentucky, May 1-4, 2010. NWS Service Assessment, 93 pp. [Available online at www.weather.gov/media/ publications/assessments/Tenn_Flooding.pdf.]

Parzybok, T. W., and B. L. Shaw, 2012: Forecast average recurrence interval precipitation maps for the United States: A new way of communicating the location and magnitude of high impact precipitation events. Preprints, 26th Conf. on Hydrology, New Orleans, LA, Amer. Meteor. Soc., 5.1. [Available online at ams.confex.com/ ams/92Annual/webprogram/Paper196778.html.]
B. Clarke, and D. M. Hultstrand, 2011: Real-time average recurrence interval rainfall maps for the U.S. Preprints, 39th Conf. on Broadcast Meteorology, Oklahoma City, OK, Amer. Meteor. Soc., 6.1. [Available online at ams.confex.com/ ams/39BROADCAST/webprogram/Paper189032.html.]

Perica, S., and Coauthors, 2013a: NOAA Atlas 14: Precipitation-frequency atlas of the United States. United States DOC/NOAA/NWS, Vol. 8, Ver. 2, 289 pp. [Available online at www.nws.noaa.gov/oh/hdsc/PF documents/Atlas14 Volume8.pdf.] , and _ 2013b: NOAA Atlas 14: Precipitationfrequency atlas of the United States. DOC/NOAA/NWS, Vol. 9, Ver. 2, 163 pp. [Available online at www.nws. noaa.gov/oh/hdsc/PF documents/Atlas 14 Volume9. pdf.]

, S. Pavlovic, M. St. Laurent, C. Trypaluk, D. Unruh, D. Martin, and O. Wilhite, 2015: NOAA Atlas 14: Precipitation-frequency atlas of the United States. DOC/ NOAA/NWS, Vol. 10, Ver. 2, 4 pp. [Available online at www.nws.noaa.gov/oh/hdsc/PF documents/Atlas 14 Volume10.pdf.]

Schroeder, A. J., and Coauthors, 2016: The development of a flash flood severity index. J. Hydrol., 541, 523-532, Crossref.

Zhang, J., and Coauthors, 2016: Multi-Radar Multi-Sensor (MRMS) quantitative precipitation estimation: Initial operating capabilities. Bull. Amer. Meteor. Soc., 97, 621-637, Crossref. 